\title{
Extremos climáticos associados à qualidade de água do Rio Guamá, São Miguel do Guamá, Pará
}

O objetivo desse trabalho visa por investigar a influência dos extremos climáticos, El Niño, na sazonalidade da precipitação e da vazão relacionados com os parâmetros de qualidade de água do Rio Guamá em São Miguel do Guamá, Pará. Sendo assim, utilizou-se os parâmetros físico químicos: pH, Oxigênio Dissolvido, Condutividade Elétrica, Sólidos Totais Dissolvidos, Temperatura da água e Turbidez. A coleta de água foi feita em três pontos caracterizados pelo despejo dos resíduos de atividades situadas nas margens do rio, PA (montante) indústria de cerâmica vermelha, PB (centro) efluentes de esgoto doméstico e PC (jusante) atividade madeireira, e através do método de regressão linear foram correlacionadas com os dados diários de precipitação $(\mathrm{mm})$ e vazão do rio $\left(\mathrm{m}^{3} / \mathrm{s}\right)$ para dois períodos distintos, chuvoso e menos chuvoso, entre os anos de 2015 e 2017. Vale ressaltar que há um padrão invertido nos dados de chuva para a região decorrente do El Niño ocorrido em 2015 a 2016. Tal situação gerou poucas chuvas na região, ocasionando assim, fortes correlações positivas e negativas entre as variáveis do sistema nos três pontos de coleta, em virtude do aumento da concentração dos resíduos orgânicos, provenientes das atividades, nas águas do rio.

Palavras-chave: Qualidade de água; Extremos climáticos; Parâmetros físico químicos; Precipitação; Vazão.

\section{Climatic extremes associated to water quality on Guamá River, São Miguel do Guamá, Pará}

\begin{abstract}
This paper intends to investigate the influence of climatic extremes, El Niño, on the seasonality of precipitation and flow related to the water quality parameters of the Guamá River in São Miguel do Guamá, Pará. For that, the chemical parameters used were: pH, Dissolved Oxygen, Electrical Conductivity, Dissolved Tota Solids, Water Temperature and Turbidity. The water collection was done at three points characterized by the dumping of waste activities located on the banks of the river, PA (upstream) red ceramics industry, PB (center) effluent from domestic sewage and PC (downstream) logging activity, and through linear regression method were correlated with daily rainfall $(\mathrm{mm})$ and river $\left(\mathrm{m}^{3} / \mathrm{s}\right)$ data for two distinct periods, rainy and less rainy, between years 2015 and 2017 . It is worth mentioning that there is an inverted pattern in the rainfall data for the El Niño region that occurred from 2015 to 2016 . This situation generated few rainfall in the region, resulting in strong positive and negative correlations between the system variables at the three collection points, due to the increase in the concentration of from the activities in the waters of the river.
\end{abstract}

Keywords: Water quality; Climatic extremes; Physical chemical parameters; Precipitation; Flow.

Topic: Meteorologia, Climatologia e Mudanças Climáticas

Reviewed anonymously in the process of blind peer
Received: 02/10/2020

Approved: 24/11/2020
Eduardo Ribeiro Marinho (iD

Universidade Federal do Pará, Brasil

http://lattes.cnpq.br/2214813622704219

http://orcid.org/0000-0002-9957-9555

educnquimica2011@hotmail.com

\section{Maria Isabel Vitorino (iD}

Universidade Federal do Pará, Brasil

http://lattes.cnpq.br/4813399912998401

http://orcid.org/0000-0003-3253-5301

vitorino@ufpa.br

Maurício do Nascimento Moura (iD

Universidade Federal do Pará, Brasil

http://lattes.cnpq.br/0278463406972552

http://orcid.org/0000-0002-2652-0587

mauriciomoura90@gmail.com
Ivan Carlos da Costa Barbosa (iD)

Universidade Federal Rural da Amazônia, Brasil

http://lattes.cnpq.br/3888979612130966

http://orcid.org/0000-0002-7358-5789

ivan.barbosa1212@gmail.com

Luiz Gonzaga da Silva Costa (iD

Universidade Federal Rural da Amazônia, Brasil

http://lattes.cnpq.br/8061175054495441

http://orcid.org/0000-0002-2701-2939

luizgonzagacosta53@gmail.com

Emerson Renato Maciel da Silva (iD

Universidade Federal do Pará, Brasil

http://lattes.cnpq.br/5581525631767986

http://orcid.org/0000-0001-8643-0826

emersonrvs255@gmail.com
Hyago Elias Nascimento Souza (iD Universidade Federal do Pará, Brasil http://lattes.cnpq.br/9712810427104066 http://orcid.org/0000-0001-8765-2981 eng.hyagosouza@gmail.com

Filipe Gomes Dias (ic

Universidade de São Paulo, Brasil http://lattes.cnpq.br/2284263711223302 http://orcid.org/0000-0003-0284-1391 dias.filipe@live.com

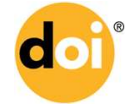

DOI: 10.6008/CBPC2179-6858.2020.006.0022
Referencing this:

MARINHO, E. R.; VITORINO, M. I.; MOURA, M. N.; BARBOSA, I. C. C.; COSTA, L. G. S.; SILVA, E. R. M.; SOUZA, H. E. N.; DIAS, F. G.. Extremos climáticos associados à qualidade de água do Rio Guamá, São Miguel do Guamá, Pará. Revista Ibero Americana de Ciências Ambientais, v.11, n.6, p.262-273, 2020. DOI: http://doi.org/10.6008/CBPC21796858.2020 .006 .0022 


\section{INTRODUÇÃO}

A água é um dos recursos naturais mais importantes à vida no planeta e sua qualidade reflete não somente suas características físicas e químicas do meio, como também, o funcionamento do ecossistema em sua magnitude (LIMA, 2001; BUENO et al., 2005). A qualidade hídrica representa um reflexo combinado entre vários fatores que ocorrem ao longo dos cursos de água (PETERS et al., 2000).

Para CETESB (2006), através da Resolução do Conselho Nacional de Meio Ambiente (CONAMA) 357/2005, são definidas como principais variáveis que ordenam os parâmetros físico químicos para avaliar a qualidade das águas: pH, Oxigênio Dissolvido, Condutividade Elétrica, Sólidos Totais Dissolvidos, Temperatura da Água e Turbidez. Embora tais variáveis se inter-relacionem, as mesmas podem sofrer influência direta da precipitação e da vazão, modificando assim suas concentrações no meio hidrológico (SILVA et al., 2008).

Segundo Marengo (2006), o ciclo hidrológico na região amazônica colabora significativamente em nível global, com a liberação de vapor de água para a atmosfera e na produção de chuvas, que irão influenciar diretamente no clima. Além das relações entre umidade atmosférica, precipitação e escoamento superficial e vazão do rio (MORAES, 2005).

A fase quente do fenômeno, El Niño Oscilação Sul (ENOS), representa um mecanismo oceanoatmosfera associado ao aquecimento anômalo da temperatura da superfície do Mar (TSM) no oceano pacífico tropical, incluindo a costa oeste da América do Sul (PEREIRA et al., 2017). Tal mecanismo afeta a circulação atmosférica global, influenciando desta forma na precipitação em diversas localidades do mundo, via teleconexão atmosférica (ANDREOLI et al., 2017), isso inclui uma redução de chuvas na Amazônia, principalmente na porção oriental (GRIMM et al., 2009; PEREIRA et al., 2017).

Nessa perspectiva, a precipitação é caracterizada amplamente pela comunidade científica como uma das variáveis climatológicas mais importantes em regiões tropicais (ALBUQUERQUE et al., 2010). O regime de chuvas no Brasil é constituído por sazonalidades distintas em estações secas e chuvosas em épocas específicas do ano de acordo com cada localização geográfica (SILVA et al., 2008).

Segundo Figueroa et al. (1990), na Amazônia oriental se observa um máximo pluviométrico entre o Pará e o Maranhão. Grande parte desse volume é verificada entre meses de dezembro a maio, o qual está atribuído em maior parte pela atuação de sistemas precipitantes de escala sinótica, como a Zona de Convergência do Atlântico Sul (ZCAS) e a Zona de Convergência Intertropical (ZCIT), também como foi mostrado por Souza et al. (2004), Souza et al. (2006). Mudanças nos padrões de circulação atmosférica, células de Walker e de Hadley, alteram a nebulosidade convectiva da ZCAS e ZCIT, modulando desta maneira a distribuição de chuvas na região amazônica (SOUZA et al., 2003; SOUZA et al., 2004).

O rio Guamá, na porção correspondente as margens do município de São Miguel do Guamá, nordeste Paraense, sofre com o despejo de resíduos de atividades econômicas, indústria de cerâmica vermelha e extração madeireira, assim como, efluentes de esgotos domésticos. Os resíduos de tais atividades são influenciados diretamente pelo regime da precipitação e vazão do rio através do escoamento superficial, 
colaborando assim em padrões de correlações estatísticas com os parâmetros físico químicos de qualidade de água.

Embora existam várias pesquisas sobre a qualidade de água do Rio Guamá, com importância significativa ao norte do Brasil, nenhum estudo focado nos impactos da precipitação e vazão deste rio ao nordeste Paraense foi realizado. Diante disso, o objetivo desse trabalho visa por investigar a influência dos extremos climáticos, El Niño, na sazonalidade da precipitação e da vazão relacionados com os parâmetros de qualidade de água do Rio Guamá em São Miguel do Guamá, Pará.

\section{MATERIAIS E MÉTODOS}

A pesquisa em questão compreende a bacia do rio Guamá, em sua localidade com a porção do município de São Miguel do Guamá, localizado no Nordeste do Estado do Pará, nas coordenadas geográficas: 10 $37^{\prime} 40^{\prime \prime}$ S, 47을 28' 55" W (Figura 1). A coleta se deu no rio Guamá, na faixa que corresponde à divisa entre os Municípios de São Miguel do Guamá e Irituia. Dividido em três pontos de coletas distintos, cada um correspondente à porção geográfica do curso de água, Ponto A, PA (Montante do rio) 1037'44.4"S 4729'24"W; Ponto B, PB (Centro do rio) 1937'26.4"S 4729'24"W; Ponto C, PC (Jusante do rio) 1937'30"S 47030'0"W. Os critérios adotados para a escolha dos pontos foram à existência de atividades econômicas e fontes de esgotamento sanitário as margens do rio do Guamá. Ponto A indústria de cerâmica vermelha; Ponto B, quatro afluentes de esgotos domésticos; Ponto $C$, atividade madeireira. As características da precipitação e vazão do rio influem diretamente no despejo de resíduos por tais atividades. Os pontos encontraram-se a uma distância de aproximadamente 200 metros um do outro.

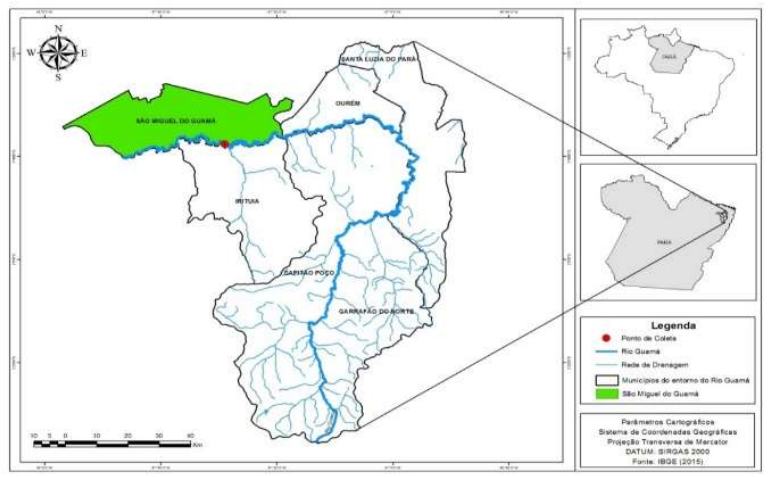

Figura 1: Mapa de Localização da Área de Estudo: Rio Guamá, Município de São Miguel do Guamá.

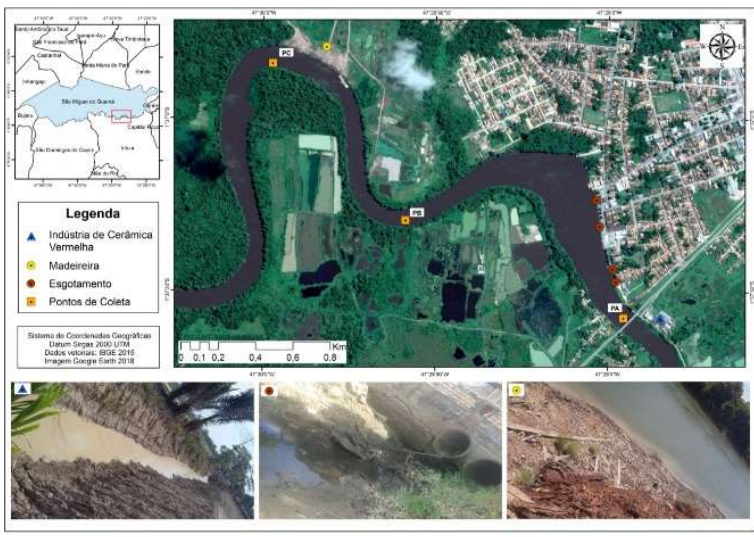

Figura 2: Localização dos pontos de coleta. Fonte: Google Earth.

\section{Dados}

As informações de qualidade de água foram obtidas por duas coletas anuais feitas durante o período de 2015 (Fev/Jul); 2016 (Jan/Jun); 2017 (Fev/Jul), totalizando um geral de seis coletas em períodos sazonais distintos. A escolha dos meses reflete a sazonalidade da região em períodos de maior e menor precipitação. Os parâmetros de análise para as variáveis físico químicas do presente estudo foram sintetizados conforme a tabela 1. A escolha de tais parâmetros além de representarem as principais variáveis que norteiam os 
estudos de qualidade de águas em rios, para CETESB (2006) e CONAMA 357/05, são as que mais sofrem influência das estações do ano (SILVA et al., 2008).

Tabela 1: Parâmetros Físico Químicos Analisados.

\begin{tabular}{llll}
\hline Parâmetro & Abreviação & Unidades & Determinação \\
\hline Potencial Hidrogeniônico & $\mathrm{pH}$ & --- & \\
Oxigênio Dissolvido & $\mathrm{OD}$ & $\mathrm{mg} \cdot \mathrm{L}^{-1}$ & Medidor multiparâmetro, HI 9829. \\
Condutividade Elétrica & $\mathrm{CE}$ & $\mu \mathrm{S} \cdot \mathrm{cm}^{-1}$ & \\
Sólidos Totais Dissolvidos & TDS & $\mathrm{mg} \cdot \mathrm{L}^{-1}$ & \\
Temperatura da Água & T.Água & oC & Oxímetro \\
& & & MO-910. \\
Turbidez & Turb & NTU & Turbidímetro \\
& & & TD 300 \\
\hline
\end{tabular}

Os dados climáticos de precipitação, foram obtidos por meio da técnica do Center Morphing Method (CMORPH), com dados estimados e interpolados com resolução 8 e 8 km (HAILE et al., 2015). Utilizaram-se dados diários de precipitação $(\mathrm{mm})$ de 30 minutos e a cada 08 quilômetros, para o período de janeiro de 2015 até Julho de 2017, distribuídos em pontos de grade para o nordeste paraense, incluindo a região de São Miguel do Guamá, com pares de coordenadas nas extremidades em 1ㅇ 37' 40" S, 47ㅇ 28’ 55" W.

Este método foi selecionado, tendo em vista não haver estações meteorológicas próximas aos pontos de coleta de água. Tal método se baseia em técnicas de sensoriamento remoto importantes na estimativa de chuvas globais, resultando em dados cujos valores são oriundos de sensores de micro-ondas de satélites geoestacionários em orbita polar (JOYCE et al., 2004; RINGARD et al., 2015).

Utilizou-se como critério do cálculo de vazão do rio Guamá, o método da regionalização de vazões mínimas em bacias através de interpolação em sistema de informação geográfica (CHAVES et al., 2002). Tal método foi escolhido tento em vista não se utilizar qualquer instrumento de medição de vazão do rio nos anos de coleta.

Sendo assim, o cálculo da razão da área de drenagem é aplicado no cálculo de vazão mínima de referência em um ponto de vazão desconhecida, dentro da área de influência de um ponto de vazão conhecida. Tem-se com isso a equação (1):

$$
Q y=\left(\frac{A y}{A x}\right) \cdot Q x(1)
$$

Onde Qy representa o ponto de Vazão no ponto de coleta da Região de São Miguel do Guamá ( $\left.\mathrm{m}^{3} / \mathrm{s}\right)$, Qx a vazão do rio Guamá na estação fluviométrica de Bom $\operatorname{Jardim}\left(\mathrm{m}^{3} / \mathrm{s}\right)$ ponto este mais próximo à área de estudo, $\mathrm{Ay}$, a área de drenagem para o ponto de coleta em São Miguel do Guamá $\left(\mathrm{m}^{2}\right)$, e $\mathrm{Ax}$ a área de drenagem do fluviómetro da estação de Bom Jardim $\left(\mathrm{m}^{3} \cdot \mathrm{s}^{-1}\right)$. Tais dados foram obtidos no site da Agência Nacional de Águas - ANA/SNIRH.

\section{Análise Estatística}

Foi aplicado o método de regressão linear, através da obtenção do coeficiente de correlação linear de Pearson $(r)$, como forma de correlacionar os parâmetros físico químicos de qualidade de água com os dados de precipitação $(\mathrm{mm})$ e vazão do rio Guamá $\left(\mathrm{m}^{3} \cdot \mathrm{s}^{-1}\right)$. Os valores de precipitação utilizados no presente estudo correspondem ao acumulado de três dias anteriores a coleta, assim como os obtidos na data da mesma.

O coeficiente de correlação linear de Pearson $(r)$ corresponde em uma medida de valores entre +1 
até -1 o qual quantifica o relacionamento linear entre séries amostrais. Para Spiegel (1972), está correlação compreende o quociente entre a covariância e o produto dos seus desvios padrões, conforme demonstrado na equação (2).

$$
\rho x, y=\frac{\operatorname{COV}(X, Y)}{\sigma X \sigma Y}
$$

Onde, COV representa a covariância; $X, Y$ das variáveis; $\sigma X \sigma Y$ o desvio padrão das variáveis. Valores próximos de +1 indicam forte correlação direta entre os parâmetros, enquanto que valores próximos de -1 indica forte correlação inversa, valores próximos de zero indicam ausência de correlação. Dancey et al. (2006) indicam uma classificação para este coeficiente, sendo que $r=0,10$ até 0,30 (fraco); $r=$ 0,40 até 0,60 (moderado); $r=0,70$ até 1 (forte).

\section{RESULTADOS E DISCUSSÃO}

A Figura 3 mostra que a precipitação e a vazão média mensal para o município de São Miguel do Guamá são similares e que apresentam duas estações bem definidas, uma chuvosa, de Janeiro a Maio, e uma menos chuvosa, de Junho a Dezembro. Vale ressaltar que a precipitação e a vazão apresentam uma defasagem de um mês entre o máximo de precipitação (Março) e o máximo de vazão (Abril). Além disso, nota-se que os valores de máximo e de mínimo de precipitação (vazão) ocorrem durante os meses de Março (Abril), com $778,5 \mathrm{~mm}\left(837,1 \mathrm{~m}^{3} \cdot \mathrm{s}^{-1}\right)$ e em Outubro (Novembro) com $43,5 \mathrm{~mm}\left(76,17 \mathrm{~m}^{3} \cdot \mathrm{s}^{-1}\right)$, respectivamente.

A variabilidade pluviométrica mensal no período chuvoso na região está relacionada com a atuação dos Vórtices Ciclônicos de Altos Níveis, a Zona de Convergência Intertropical (ZCIT) e os sistemas convectivos de mesoescala (SCM), e um período menos chuvoso influenciado principalmente pelos Distúrbios Ondulatórios de Leste e os SCM (SOUZA et al., 2004; AMANAJÁS et al., 2012; CAMPONOGARA et al., 2011; GERMANO et al., 2017).

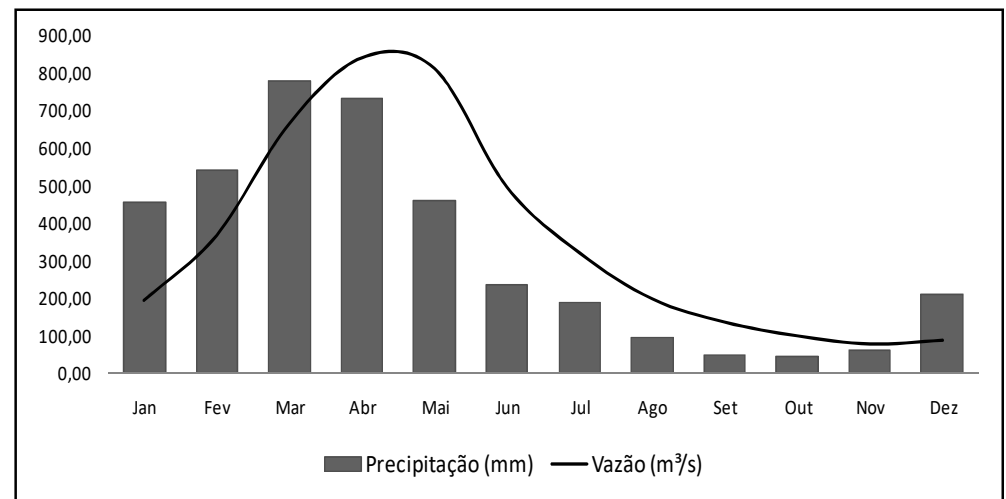

Figura 3: Distribuição normal da precipitação $(\mathrm{mm})$ e da vazão do Rio Guamá $\left(\mathrm{m}^{3} / \mathrm{s}\right)$ do Município de São Miguel do Guamá para o período de 1998 a 2017.

A figura 4 mostra as anomalias mensais de precipitação e de vazão do rio Guamá, durante o período de coleta de água (2015 a 2017), com valores preferencialmente negativos de chuva e vazão em 2015 e 2016 , evidenciando quantitativos abaixo da normal para a região, exceto para o período chuvoso de 2017. Isto está relacionado com a ocorrência dos Índices de Oscilação Sul (IOS) em sua fase negativa que representa o EI Niño, desde Agosto de 2014 (não mostrado) até Maio de 2016, quando se observa a mudança de fase do IOS 
para valores positivos, ou seja, a fase da La Niña. Segundo a literatura a região norte e nordeste do Brasil sofre redução de chuvas durante o El Niño, e aumento das chuvas na La Niña (GRIMM et al., 2009; PEREIRA et al., 2017).

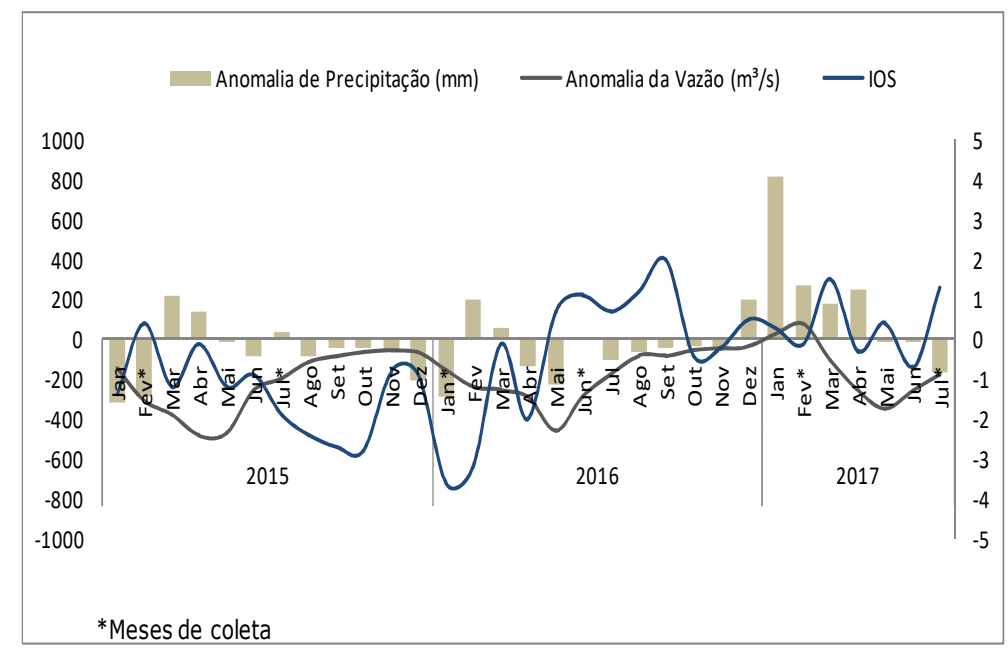

Figura 4: Anomalia mensal de precipitação $(\mathrm{mm})$ e vazão do Rio Guamá $\left(\mathrm{m}^{3}\right.$ /s) do Município de São Miguel do Guamá para os anos de 2015 a 2017.

A figura 5 mostra a forte correlação positiva entre os acumulados diários de precipitação $(\mathrm{mm})$ e vazão do Rio Guamá $\left(\mathrm{m}^{3} / \mathrm{s}\right)(\mathrm{r}=0,81)(\mathrm{p}<0,05)$. Para Fritzsons et al. (2003), Medeiros et al. (2009) e Santos et al. (2013) a precipitação contribui diretamente para o aumento dos valores de vazão do rio, evidenciando uma proporção direta e linear entre a magnitude das variáveis.

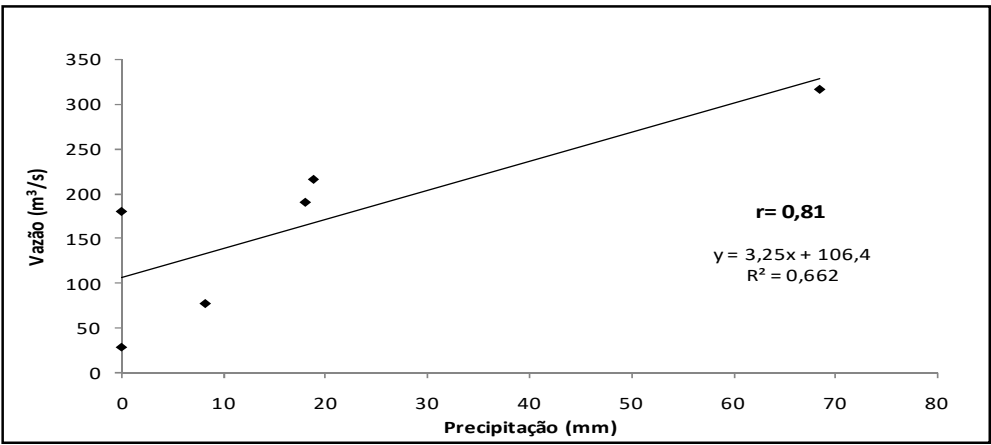

Figura 5: Correlação entre os acumulados diários de precipitação $(\mathrm{mm})$ e Vazão do Rio Guamá $\left(\mathrm{m}^{3} / \mathrm{s}\right)$.

\section{A influência da precipitação na qualidade de água do rio Guamá}

A tabela 2 representa a correlação existente entre os parâmetros físico químicos de qualidade de água, $\mathrm{pH}, \mathrm{OD}, \mathrm{CE}, \mathrm{TDS}, \mathrm{T}$.Água, TURB e a precipitação diária $(\mathrm{mm})$ para os três pontos de coleta, PA (montante), PB (centro) e PC (jusante) no rio Guamá. É observado a predominância de fortes correlações negativas $r<-0,7$ (positivas $r>0,7$ ), entre $p H, O D, C E, T D S, T$.Água (TURB) com a precipitação na região para os três pontos no período chuvoso (Fev/2015, Jan/2016, Fev/2017). Como também, fortes correlações negativas entre ph, OD nos três pontos de coleta no período menos chuvoso (Jul/2015, Jun/2016, Jul/2017), com exceção do OD em PA (Jul/2015). As demais correlações demonstraram ser moderadas ou fracas.

A influência da precipitação diária nas correlações de regressão linear com os parâmetros físico químicos de qualidade de água, em um período de extremo climático, El Niño, mostra uma inversão na 
interpretação dos valores de chuvas para a região de São Miguel do Guamá, ou seja, o período chuvoso, com poucas chuvas, quando se comparado ao período menos chuvoso dos anos de coleta de água. Tal fato pode ser a justificativa das fortes correlações existentes entre os parâmetros de qualidade de água no meses de Jan e Fev nos três anos de coleta. Embora diminua a carga externa de nutrientes sobre o curso d'água em virtude de redução da quantidade de chuvas, a carga interna aumenta pois há uma maior concentração dos mesmos no meio (JEPPESEN et al., 2015).

Tabela 2: Correlação entre os Parâmetros Físico Químicos de qualidade de água e a precipitação diária (mm) para os três pontos de coleta em períodos sazonais distintos, $\mathrm{CH}$ : Chuvoso; $\mathrm{MCH}$ : Menos Chuvoso.

\begin{tabular}{|c|c|c|c|c|c|c|}
\hline \multicolumn{7}{|c|}{ Coeficiente de Correlação Linear de Pearson(r) } \\
\hline \multirow[t]{2}{*}{ Parâmetro por Ponto } & \multicolumn{2}{|l|}{ Ponto A } & \multicolumn{2}{|l|}{ Ponto B } & \multicolumn{2}{|l|}{ Ponto C } \\
\hline & $\mathrm{CH}$ & $\mathrm{MCH}$ & $\mathrm{CH}$ & $\mathrm{MCH}$ & $\mathrm{CH}$ & $\mathrm{MCH}$ \\
\hline $\mathrm{pH}$ & $-0,89 *$ & $-0,99 *$ & $-0,98^{*}$ & $-0,92^{*}$ & $-0,98^{*}$ & $-0,83^{*}$ \\
\hline $\mathrm{OD}\left(\mathrm{mg} \cdot \mathrm{L}^{-1}\right)$ & $-0,99 *$ & $-0,32$ & $-0,92 *$ & $-0,72 *$ & $-0,95^{*}$ & $-0,72 *$ \\
\hline $\mathrm{CE}\left(\mu \mathrm{S} . \mathrm{cm}^{-1}\right)$ & $-0,99 *$ & 0,40 & $-0,95 *$ & 0,58 & $-0,98 *$ & $-0,12$ \\
\hline TDS (mg. L-1) & $-0,98^{*}$ & 0,37 & $-0,98 *$ & 0,46 & $-0,99 *$ & $-0,29$ \\
\hline T.Água (으) & $-0,87^{*}$ & $-0,06$ & $-0,89 *$ & $-0,12$ & $-0,89 *$ & $-0,29$ \\
\hline TURB (NTU) & $0,98^{*}$ & $-0,60$ & $0,94 *$ & $-0,43$ & $0,96 *$ & $-0,01$ \\
\hline
\end{tabular}

${ }^{*}$ Coeficientes de correlação fortes

$\mathrm{O}$ pH das águas do rio Guamá apresenta forte correlação negativa com a precipitação diária nos três pontos de coleta, PA, PB e PC para os dois períodos, chuvoso e menos chuvoso, pois é influenciado pela lixiviação dos solos ácidos amazônicos e pela grande quantidade de matéria orgânica que se decompõem na forma de ácidos orgânicos (ESTEVES, 1998; CUNHA et al., 2006; PINTO et al., 2009). Segundo Esteves (1998), no Brasil, ecossistemas aquáticos continentais com pH baixo são encontrados em regiões de terra firme da Amazônia central, podendo corpos d'água apresentarem valores de pH ácidos. $\mathrm{O}$ pH reflete o tipo de solo por onde a água percorre e é influenciado pelo regime de precipitação da região (GOMES, 2009).

A forte correlação negativa de OD e precipitação, também é verificada nos três pontos de coleta, $P A$, PB e PC para o período sazonal, com exceção para o período menos chuvoso em PA (montante). Tal característica pode estar relacionada à quantidade de madeira oriunda da atividade madeireira em PC (jusante), e resíduos de esgotamento sanitário em PB (centro), que atrelados a um baixo volume de precipitação, associado ao El Niño, acarretam maiores processos de consumo de oxigênio na água. O acréscimo de matéria orgânica no interior dos rios provoca o consumo de oxigênio aquático pela oxidação química e bioquímica, através da respiração dos micro-organismos que depuram a matéria orgânica existente no meio aquático (PINTO, 2003; MIRANDA et al., 2009; GOMES, 2009).

As correlações existentes entre CE com a precipitação para os três pontos de coleta revelam que mesmo sendo um período de extremo climático, El Niño, CE apresenta um comportamento de correlações específico, em fortes correlações para o período chuvoso e moderadas e fracas correlações para o período menos chuvoso dos anos de coleta de água. Isso pode ser justificado segundo os trabalhos de Lima (2001); Esteves (1998); que abordam que em regiões tropicais, como a região amazônica, valores de condutividade presentes em ambientes aquáticos estão interligados com os aspectos climáticos do meio, devendo-se considerar a sazonalidade da região em períodos de menor precipitação (SILVA et al., 2008).

Os sólidos totais dissolvidos apresentam correlação com a precipitação diária, semelhante ao item 
anterior, forte negativa (fraca negativa) para o período chuvoso (menos chuvoso), tal fato é explicado segundo Gomes (2009) e Araújo et al. (2013), que defendem uma relação direta entre CE e TDS, pois sendo a condutividade uma medida de carga iônica de amostras, a mesma está intimamente relacionada à presença de sólidos dissolvidos no meio.

As correlações existentes entre T.Água e precipitação diária, forte negativa (fraca negativa) para o período chuvoso (menos chuvoso), justificam que períodos de altas T.Água na Amazônia diferem dos períodos de maior precipitação (MIRANDA et al., 2009; ALVES et al., 2012). Para Sá Filho (2010) e Alves et al. (2012), esta influência está relacionada com a cobertura de nuvens, que no período chuvoso dificultam a incidência dos raios solares sobre as águas do rio, diferentemente do período menos chuvoso o qual a incidência solar sobre as águas é mais intensa. Entretanto, se tratando de um período de El Niño, poucas chuvas, ocorre alta incidência de raios solares sobre o rio Guamá, destacando as fortes correlações existentes entre T.Água e precipitação para os meses Fev e Jan do período de estudo.

A turbidez apresentou correlações fortes positivas (fracas e moderadas positivas) para o período chuvoso (menos chuvoso) nos três pontos de coleta de água. Tal classificação pode ser justificada segundo a literatura pertinente a qualidade de água e precipitação, o qual explica que em períodos chuvosos os valores de turbidez tendem a diminuir, e em períodos menos chuvosos tendem a aumentar (PINTO et al., 2009; SILVA et al., 2008). O El Niño verificado nos anos de coleta, fez com que no período chuvoso a correlação de Turb e vazão fossem mais elevadas do que no período menos chuvoso, destacando assim as fortes correlações existentes para os meses de Jan e Fev dos anos de coleta.

\section{Vazão e qualidade de água}

A tabela 3 mostra a correlação existente entre os parâmetros físico químicos de qualidade de água, $\mathrm{pH}, \mathrm{OD}, \mathrm{CE}, \mathrm{TDS}, \mathrm{T} . A ́ g u a$, TURB e a vazão diária $\left(\mathrm{m}^{3} \cdot \mathrm{s}^{-1}\right)$ para os três pontos de coleta, PA (montante), PB (centro) e PC (jusante) no rio Guamá. Verifica-se a existência de fortes correlações negativas $r<-0,7$ (positivas $r>0,7$ ), entre $p H, O D, C E, T D S, T$.Água (TURB) nos três pontos no período chuvoso (Fev/2015, Jan/2016, Fev/2017). Fortes correlações negativas também foram verificadas para pH, OD, T.Água, TURB no período menos chuvoso (Jul/2015, Jun/2016, Jul/2017), com exceção para pH em PB, TURB em PC. As demais correlações classificaram-se como moderadas ou fracas.

Tabela 3: Correlação entre os Parâmetros Físico Químicos de qualidade de água e a vazão diária $\left(\mathrm{m}^{3} / \mathrm{s}\right)$ para os três pontos de coleta em períodos sazonais distintos, $\mathrm{CH}$ : Chuvoso; $\mathrm{MCH}$ : Menos Chuvoso.

\begin{tabular}{|c|c|c|c|c|c|c|}
\hline \multirow{3}{*}{ Parâmetro } & \multicolumn{6}{|c|}{ Coeficiente de Correlação Linear de Pearson(r) } \\
\hline & Ponto A & & Ponto B & & Ponto $\mathrm{C}$ & \\
\hline & $\mathrm{CH}$ & $\mathrm{MCH}$ & $\mathrm{CH}$ & $\mathrm{MCH}$ & $\mathrm{CH}$ & $\mathrm{MCH}$ \\
\hline $\mathrm{pH}$ & $-0,91^{*}$ & $-0,81^{*}$ & $-0,99 *$ & $-0,43$ & $-0,99 *$ & $-0,99 *$ \\
\hline OD (mg. $\left.\mathrm{L}^{-1}\right)$ & $-0,99 *$ & $-0,87^{*}$ & $-0,90 *$ & $-0,99 *$ & $-0,94 *$ & $-0,99 *$ \\
\hline CE $\left(\mu S . \mathrm{cm}^{-1}\right)$ & $-0,99 *$ & $-0,30$ & $-0,96 *$ & $-0,10$ & $-0,99 *$ & 0,56 \\
\hline TDS (mg. $\left.\mathrm{L}^{-1}\right)$ & $-0,99 *$ & $-0,33$ & $-0,99 *$ & $-0,24$ & $-0,99 *$ & 0,41 \\
\hline T.Água (으) & $-0,89 *$ & $-0,71^{*}$ & $-0,91^{*}$ & $-0,75^{*}$ & $-0,91^{*}$ & $-0,85^{*}$ \\
\hline TURB (NTU) & $0,99 *$ & $-0,98^{*}$ & $0,95^{*}$ & $-0,92^{*}$ & $0,97^{*}$ & $-0,67$ \\
\hline
\end{tabular}

*Coeficientes de correlação fortes.

É destaque no presente estudo, uma quantidade maior de correlações fortes entre os parâmetros de 
qualidade de água e os valores de vazão do rio $\left(\mathrm{m}^{3} \cdot \mathrm{s}^{-1}\right)$ no período chuvoso, em detrimento das correlações dos mesmos parâmetros com os dados de precipitação diária $(\mathrm{mm})$ para o mesmo período. Tal fato pode ser justificado pelas poucas chuvas ocorridas nos anos de coleta, El Niño, diminuírem o nível de água no rio, ocasionando assim um aumento na concentração dos parâmetros existentes no meio (BARBOSA et al., 2012; JEPPESEN et al., 2015), e consequentemente uma maior correlação destes parâmetros com a vazão do rio.

A forte correlação negativa existente entre o pH da água e vazão do rio para os três pontos de coleta, PA, PB PC, tanto no período chuvoso quanto no menos chuvoso, evidencia que há uma tendência da diminuição do pH com o aumento da vazão do rio. Situação também constatada nos trabalhos de Alvarenga et al. (2012), Queiroz et al. (2013), Carvalho et al. (2010). Tais autores defendem a necessidade de não atribuir somente a vazão a explicação pelas alterações nos valores de $\mathrm{pH}$, tendo em vista o rio ser um ambiente dinâmico influenciado por vários outros fatores, tais como; temperatura, gases dissolvidos, sólidos, fatores abióticos.

O Oxigênio dissolvido apresentou fortes correlações negativas nos três pontos de coleta para o período chuvoso e menos chuvoso. Essa característica pode estar associada na relação existente entre a concentração de OD com as variações sazonais de turbulência da água e vazão do rio (BARROS et al., 2012). Alves et al. (2012), afirmam que elevadas concentrações de oxigênio dissolvido ocorrem durante o período menos chuvoso, pois o nível da água diminui, favorecendo a elevação das taxas de oxigênio no rio. Fato que justifica no presente estudo, as fortes correlações negativas de OD e vazão para o período chuvoso, que sendo El Niño apresentou poucas chuvas, e para o período menos chuvoso dos anos de coleta de água.

A forte correlação negativa entre CE e vazão do rio Guamá, foi observada para os três pontos de coleta de água somente para o período chuvoso. Tal correlação deve-se ao fato da redução do volume de chuvas, e consequentemente da vazão do rio, fazer com que aumente a concentração de sais dissolvidos na água, e assim se eleve os valores de CE (VANZELA, 2004). Para Rocha et al. (2010) e Santos et al. (2013), a variação sazonal de CE com a vazão, está intimamente relacionada ao regime de precipitação em uma determinada região.

A correlação entre TDS e vazão do rio assemelha-se à observada no item anterior, forte negativa para os três pontos de coleta de água somente para o período chuvoso. Estando TDS em uma relação extremamente direta com CE (GOMES, 2009), espera-se que esta relação inversa de proporcionalidade, esteja explicada também, pelo aumento da concentração de sais presentes na água, quando a vazão do rio se encontra baixa.

A forte correlação negativa para T.Água e vazão do rio, e diagnosticada nos três pontos de coleta, PA, PB, PC durante o período chuvoso e menos chuvoso. Segundo Alvarenga et al. (2012) T.Água é um dos parâmetros de qualidade de água mais influenciado pela sazonalidade da vazão. Tal característica está intimamente relacionada às chuvas na região, que no período menos chuvoso apresenta os menores valores de vazão do rio, as taxas de temperatura da água aumentam em decorrência da menor quantidade de nuvens na região (ALVES et al., 2012).

Turbidez apresentou forte correlação positiva (negativa) em todos os pontos de coleta, PA, PB, PC 
para o período chuvoso (menos chuvoso). A correlação negativa está de acordo com o que diz Jeppesen et al. (2015), onde períodos com poucas chuvas, acarretam valores elevados de TURB, pois são influenciados pelo aumento dos sólidos inorgânicos causados pela ressuspensão de sedimentos em um período com baixa profundidade da coluna de água. Na literatura, a correlação positiva está relacionada à presença das chuvas, que causando maiores vazões, favorecem a entrada de materiais particulados na água em decorrência do escoamento superficial (OLIVEIRA et al., 2008; MEDEIROS et al., 2009; SANTOS et al., 2013; BARRETO et al., 2014).

\section{CONCLUSÕES}

Este trabalho verificou a existência de fortes correlações negativas entre os parâmetros de qualidade de água do Rio Guamá e os valores de precipitação e vazão, preferencialmente, no período chuvoso dos anos de coleta (Fev/2015, Jan/2016, Fev/2017). Vale ressaltar que o referido período apresenta um padrão invertido na precipitação, pois sofreu a influência do El Niño, 2015 e 2016, havendo assim uma redução de chuvas na região quando comparado ao período menos chuvoso (Jul/2015, Jun/2016, Jul/2017).

Este fato pode ser caracterizado como o principal motivo das fortes correlações existentes, haja vista que com a redução da precipitação, e consequentemente a diminuição da vazão do rio, a concentração da matéria orgânica proveniente dos resíduos das atividades do entorno do rio aumenta, alterando assim a resposta dos parâmetros no meio aquático.

Em síntese são verificadas fortes correlações entre $\mathrm{pH}, \mathrm{OD}(\mathrm{pH}, \mathrm{OD}, \mathrm{T}$.Água, TURB) e a precipitação (vazão do rio) para os três pontos de coleta PA (montante), PB (centro), PC (jusante) durante o período chuvoso, que sofreu com a redução das chuvas, com exceção de OD em PA (pH em PB, TURB em PC). TURB foi a única variável que apresentou fortes correlações positivas para o período chuvoso entre as séries amostrais. É importante destacar o papel que a sazonalidade da precipitação e a dinâmica da vazão têm na correlação com os parâmetros físico químicos de qualidade de água do Rio Guamá, em São Miguel do Guamá - PA. O presente estudo mostra-se inovador para a região, tendo em vista ser pioneiro na temática dos extremos climáticos associados à qualidade de água no Nordeste Paraense.

O método das correlações lineares, coeficiente de Pearson ( $r$ ), foi utilizado para o melhor entendimento da relação estatística e proporcional existente entre os parâmetros de qualidade de água e as outras variáveis que interferem no sistema. Para analisar a qualidade de água em um rio de maneira correta, é necessário entender sobre todas as vertentes que influem de maneira direta ou indireta no mesmo. Tal metodologia mostra-se eficiente em abordagens interdisciplinares sobre avaliação da qualidade hídrica de rios e problemáticas ambientais.

\section{REFERÊNCIAS}

ALBUQUERQUE, M. F.; SOUZA, E. B.; OLIVEIRA, M. D. C. F.; SOUZA JÚNIOR, J. A.. Precipitação nas mesorregiões do estado do Pará: climatologia, variabilidade e tendências nas últimas décadas (1978-2008). Revista Brasileira de Climatologia, v.6, 2010.
DOI: http://dx.doi.org/10.5380/abclima.v6i0.25606

ALVARENGA, L. A.; MARTINS, M. P. P.; CUARTAS, L. A.; PENTEADO, V. A.; ANDRADE, A.. Estudo da qualidade e quantidade da água em microbacia, afluente do rio Paraíba 
do Sul-São Paulo, após ações de preservação ambiental. Revista Ambiente \& Água, v.7, n.3, p.228-240, 2012. DOI: http://dx.doi.org/10.4136/ambi-agua.987

ALVES, I. C. C.; EL-ROBRINI, M.; SANTOS, M. D. L. S.; MONTEIRO, S. D. M.; BARBOSA, L. P. F.; GUIMARÃES, J. T. F. Qualidade das águas superficiais e avaliação do estado trófico do Rio Arari (Ilha de Marajó, norte do Brasil). Acta Amazonica, v.42, n.1, p.115-124, 2012. DOI: http://dx.doi.org/10.1590/S0044-59672012000100014

AMANAJÁS, J. C.; BRAGA, C. C.. Padrões espaço-temporal pluviométricos na Amazônia Oriental utilizando análise multivariada. Revista Brasileira de Meteorologia, v.27, n.4, p.423-434, 2012. DOI: http://dx.doi.org/10.1590/S0102 77862012000400006

ANDREOLI, R. V.; OLIVEIRA, S. S.; KAYANO, M. T.; VIEGAS, J.; SOUZA, R. A. F.; CANDIDO, L. A.. The influence of different EI Niño types on the South American rainfall. International Journal of Climatology, v.37, n.3, p.1374-1390, 2017. DOI: https://doi.org/10.1002/joc.4783

ARAÚJO, M. C. D.; OLIVEIRA, M. B. M. D.. Monitoramento da qualidade das águas de um riacho da Universidade Federal de Pernambuco, Brasil. Revista Ambiente \& Água, v.8, n.3, p.247-257, 2013. DOI: https://doi.org/10.4136/ambiagua.1192

BARBOSA, J. E. D. L.; MEDEIROS, E. S. F.; BRASIL, J.; CORDEIRO, R. D. S.; CRISPIM, M. C. B.; SILVA, G. H. G. D.. Aquatic systems in semi-arid Brazil: limnology and management. Acta Limnologica Brasiliensia, v.24, n.1, p.103-118, 2012. DOI: https://doi.org/10.1590/s2179975X2012005000030

BARRETO, L. V.; FRAGA, M. D. S.; BARROS, F. M.; ROCHA, F. A.; AMORIM, J. D. S.; CARVALHO, S. R. D.; SILVA, D. P. D.. Relação entre vazão e qualidade da água em uma seção de rio. Revista Ambiente e Água, v.9, n.1, 2014.

BARROS, F. M.; MARTINEZ, M. A.; DE MATOS, A. T.; MOREIRA, D. A.. Distribuição quantitativa de variáveis de qualidade da água coletada em diferentes pontos de um perfil transversal do rio Turvo Sujo, MG. Revista Engenharia na Agricultura-Reveng, v.20, n.1, p.60-69, 2012. DOI: https://doi.org/10.13083/reveng.v20i1.205

BUENO, L. F.; GALBIATTI, J. A.; BORGES, M. J..

Monitoramento de variáveis de qualidade da água do Horto Ouro Verde-Conchal-SP. Engenharia Agrícola, v.25, n.3, p.742-748, 2005. DOI: http://dx.doi.org/10.1590/S0100$\underline{69162005000300020}$

CAMPONOGARA, G.; DIAS, M. A. F. S.. Precipitação diária e estrutura vertical da atmosfera em Belém, PA. Ciência e Natura, p.263-266, 2011.

CARVALHO, G. L. D.; SIQUEIRA, E. Q. D.. Qualidade da água do Rio Meia Ponte no perímetro urbano do município de Goiânia-Goiás. Revista Eletrônica de Engenharia Civil, v.2, n.1, 2011. DOI: https://doi.org/10.5216/reec.v2i1.12293

CETESB. Companhia Ambiental do Estado de São Paulo. Variáveis de qualidade das águas. São Paulo: CETESB, 2006.

CHAVES, H. M. L.; ROSA, J. W. C.; VADAS, R. G.; OLIVEIRA, R.
V.. Regionalização de vazões mínimas em bacias através de interpolação em sistemas de informação geográfica. Revista Brasileira de Recursos Hídricos, v.7, n.3, p.43-51, 2002.

CONAMA. Conselho Nacional do Meio Ambiente. Resolução n. 357 de 17 de Março de 2005. Parâmetros de qualidade de água. Brasília: CONAMA, 2005.

CUNHA, H. B. D.; PASCOALOTO, D.. Hidroquímica dos rios da Amazônia. Manaus: Centro cultural dos povos da Amazônia, 2006.

DANCEY, C; REIDY, J.. Estatística sem matemática para Psicologia: Usando SPSS para Windows. 3 ed. Porto Alegre: Artmed, 2006.

ESTEVES, F. A.. Fundamentos of Limnology. 2 ed. New York Interciência, 1998.

FIGUEROA, S. N.; NOBRE, C. A.. Precipitation distribution over central and western tropical South America. Climanalise, v.5, n.6, p.36-45, 1990.

FRITZSONS, E.; HINDI, E. C.; MANTOVANI, L. R.; RIZZI, N. E. As alterações da qualidade da água do Rio Capivari com o deflúvio: um instrumento de diagnóstico de qualidade ambiental. Engenharia Sanitária e Ambiental, v.8, n.4, p.239-248, 2003.

GERMANO, M. F.; VITORINO, M. I.; COHEN, J. C. P.; COSTA G. B.; SOUTO, J. I. D. O.; REBELO, M. T. C.; SOUSA, A. M. L.. Analysis of the breeze circulations in Eastern Amazon: an observational study. Atmospheric Science Letters, v.18, n.2, p.67-75, 2017. DOI: https://doi.org/10.1002/asl.726

GOMES, L. H.. Alterações de propriedades físico químicas da água tratada com preparados homeopáticos de carbonato de cálcio. Dissertação (Mestrado em Fitotecnia) Universidade Federal de Viçosa, Viçosa, 2009.

GRIMM, A. M.; AMBRIZZI, T.. Teleconexões na América do Sul a partir de trópicos e extratrópicos em escalas interanuais e intrazazais. In: No passado, variabilidade climática na América do Sul e regiões adjacentes. Springer, 2009. p.159-191.

HAILE, A. T.; YAN, F.; HABIB, E.. Accuracy of the CMORPH satellite-rainfall product over Lake Tana Basin in Eastern Africa. Atmospheric Research, v.163, p.177-187, 2015. DOI: https://doi.org/10.1016/j.atmosres.2014.11.011

JEPPESEN, E.; BRUCET, S.; NASELLI-FLORES, L.; PAPASTERGIADOU, E.; STEFANIDIS, K.; NOGES, T.; BUCAK, T.. Impactos ecológicos do aquecimento global e da captação de água em lagos e reservatórios devido a mudanças no nível da água e mudanças relacionadas na salinidade. Hydrobiologia, v.750, n.1, p.201-227, 2015.

JOYCE, R. J.; JANOWIAK, J. E.; ARKIN, P. A.; XIE, P.. CMORPH: A method that produces global precipitation estimates from passive microwave and infrared data at high spatial and temporal resolution. Journal of hydrometeorology, v.5, n.3, p.487-503, 2004. DOI: https://doi.org/10.1175/15257541(2004)005<0487:CAMTPG>2.0.CO;2

LIMA, E. B. N. R.. Modelação integrada para gestão da qualidade da água na bacia do rio Cuiabá. Tese (Doutorado 
em Ciências em Engenharia Civil) - Universidade Federal do Rio de Janeiro, Rio de Janeiro, 2001.

MARENGO, J. A.. Sobre o ciclo hidrológico da Bacia Amazônica: uma revisão histórica e o estado da arte atual. Revista Brasileira de Meteorologia, v.21, n.3, p.1-19, 2006.

MEDEIROS, G. A.; ARCHANJO, P.; SIMIONATO, R.; REIS, F. A. G. V.. Diagnóstico da qualidade da água na microbacia do córrego recanto, em americana, no estado de São Paulo. Geosciences, v.28, n.2, p.181-191, 2009.

MIRANDA, R. G.; PEREIRA, S. D. F. P.; ALVES, D. T. V.; OLIVEIRA, G. R. F.. Qualidade dos recursos hídricos da Amazônia-Rio Tapajós: avaliação de caso em relação aos elementos químicos e parâmetros físico-químicos. Ambiente \& Água-An Interdisciplinary Journal of Applied Science, v.4, n.2, p.75-92, 2009. DOI: https://doi.org/10.4136/1980-993x

MORAES, B. C. D.; COSTA, J. M. N. D.; COSTA, A. C. L. D.; COSTA, M. H.. Variação espacial e temporal da precipitação no estado do Pará. Acta Amazônica, v.35, n.2, p.207-214, 2005. DOI: https://doi.org/10.1590/S004459672005000200010

OLIVEIRA, L. C. D.; GOMES, B. M.; BAUMGARTNER, G.; SEBASTIEN, N. Y.. Variação espacial e temporal dos fatores limnológicos em riachos da microbacia do Rio São Francisco Verdadeiro. Engenharia Agrícola, v.28, n.4, p.770-781, 2008. DOI: http://dx.doi.org/10.1590/S0100-69162008000400017

PEREIRA, H. R.; REBOITA, M. S.; AMBRIZZI, T.. Características da atmosfera na primavera australiana durante o El Niño de 2015/2016. Revista Brasileira de Meteorologia, v.32, n.2, p.293-310, 2017. DOI: https://doi.org/10.1590/010277863220011

PETERS, N. E.; MEYBECK, M.. Efeitos da degradação da qualidade da água na disponibilidade de água doce: impactos das atividades humanas. Water International, v.25, n.2, p.185-193, 2000. DOI: https://doi.org/10.1080/02508060008686817

PINTO, A. G. N.; HORBE, A. M. C.; SILVA, M. D. S. R. D.; MIRANDA, S. A. F.; PASCOALOTO, D.; SANTOS, H. M. D. C.. Efeitos da ação antrópica sobre a hidrogeoquímica do rio Negro na orla de Manaus/AM. Acta Amazônica, v.39, n.3, p.627-638, 2009. DOI: https://doi.org/10.1590/S0044$\underline{59672009000300018}$

PINTO, A. L.. Saneamento Básico e Qualidade das Águas Subterrâneas. In: MORETTI, E. C.; CALIXTO, M. J. M. S.. Geografia e Produção Regional: Sociedade e Ambiente. Campo Grande: UFMS, 2003. p.11-55.
QUEIROZ, M. M. F.; DANTAS, E. F.; SILVA, A. L.. Qualidade e quantidade da água do rio Piancó, Teibutário do rio Piranhas Açu na região nordeste. Revista Verde de Agroecologia e Desenvolvimento Sustentável, v.8, n.2, p.8, 2013.

RINGARD, J.; BECKER, M.; SEYLER, F.; LINGUET, L.. Temporal and spatial assessment of four satellite rainfall estimates over French Guiana and North Brazil. Remote Sensing, v.7, n.12, p.16441-16459, 2015. DOI:

https://doi.org/10.3390/rs71215831

ROCHA, F. A.; OLIVEIRA, M. S. C.; MELO, A.; BARROS, F.; BARRETO, L.. Variáveis de qualidade de água influenciadas pelo tipo e época de amostragem, no rio Catolé/BA. Enciclopédia Biosfera, Goiânia, v.6, n.11, 2010.

SÁ FILHO, J. A. R.. Avaliação qualitativa das águas no sistema da macrodrenagem da Bacia do Tabuleiro do Martins-Maceió/AL. Dissertação (Mestrado em Recursos Hídricos e Saneamento Ambiental) - Universidade Federal de Alagoas, Maceió, 2010.

SANTOS, Q. R.; FRAGA, M. S.; ULIANA, E. M.; REIS, A. S.; BARROS, F. M.. Monitoramento da qualidade da água em uma seção transversal do rio Catolé, Itapetinga-BA. 2013.

SILVA, A. E. P.; ANGELIS, C. F.; MACHADO, L. A. T.; WAICHAMAN, A. V.. Influência da precipitação na qualidade da água do Rio Purus. Acta Amazônica, v.38, n.4, p.733-742, 2008. DOI: https://doi.org/10.1590/S0044$\underline{59672008000400017}$

SOUZA, E. B.; ROCHA, E. J. P.. Variações diurnas das chuvas em Bragança-PA (leste da Amazônia) durante a estação chuvosa: características médias e eventos extremos. Revista Brasileira de Meteorologia, v.21, n.3, p.142-152, 2006.

SOUZA, E. D.; AMBRIZZI, T.. Pentad precipitation climatology over Brazil and the associated atmospheric mechanisms. Climanálise, v.2, n.1, 2003.

SOUZA, E. D.; KAYANO, M. T.; AMBRIZZI, T.. The regional precipitation over the eastern Amazon/northeast Brazil modulated by tropical Pacific and Atlantic SST anomalies on weekly timescale. Revista Brasileira de Meteorologia, v.19, n.2, p.113-122, 2004.

SPIEGEL, M. R.. Estatística. São Paulo: McGraw-HILL, 1972.

VANZELA, L. S.. Qualidade de água para a irrigação na microbacia do córrego Três Barras no município de Marinópolis, SP. Dissertação (Mestrado em Agronomia) Universidade Estadual Paulista, Ilha Solteira, 2004.

A CBPC - Companhia Brasileira de Produção Científica (CNPJ: 11.221.422/0001-03) detém os direitos materiais desta publicação. Os direitos referem-se à publicação do trabalho em qualquer parte do mundo, incluindo os direitos às renovações, expansões e disseminacões da contribuiç̃o, bem como outros direitos subsidiários. Todos os trabalhos publicados eletronicamente poderão posteriormente ser publicados em coletâneas impressas sob coordenação da Sustenere Publishing da Companhia Brasileira de Produção Científica e seus parceiros autorizados. Os (as) autores (as) preservam os direitos autorais, mas não têm permissão para a publicação da contribuição em outro meio, impresso ou digital, em português ou em tradução. 